Boise State University

ScholarWorks

6-1-2012

\title{
The Emergence and Future of Near-Surface Geophysics
}

William E. Doll

Battelle-Oak Ridge Operations

Richard D. Miller

Kansas Geological Survey

John Bradford

Boise State University 


\title{
The emergence and future of near-surface geophysics
}

\author{
Wilıam E. Dolı, Battelle-Oak Ridge Operations \\ Richard D. Miller, Kansas Geological Survey \\ JoHn BRADFORD, Boise State University
}

$\mathrm{O}_{2}$

ver the past 30 years, geophysical methods have assumed a much more prominent and integral role in many investigations where subsurface features have environmental and engineering importance. In fact, the field once referred to as "environmental and engineering geophysics" has broadened to include other applications (e.g., archeology, forensics), and is now commonly referred to more generally as "near-surface geophysics."

It is difficult to precisely define near-surface geophysics, and the definition will likely depend on whom you ask. However, we define it as the use of geophysical methods to investigate the zone between the surface and hundreds of meters into the Earth's crust. Applications include, but are not limited to, potable water management, engineered infrastructure and construction, site clearance, gas storage, natural-hazard mitigation, mining, forensics, and archaeology. Although the same physical principles are relevant for any target depth, the high degree of near-surface heterogeneity, rapid change in physical properties, and proximity to the free surface often dictates that dominant processes and therefore key assumptions differ between the near-surface and deeper investigations. While near-surface geophysics shares many technical and cultural attributes of oil and gas exploration, the majority of near-surface geophysicists practice under different economic drivers and conditions.

By many projections, the growth of near-surface geophysics is expected to continue throughout the current century, as methodologies continue to advance and become more widely accepted, as population expansion encroaches on challenging geologic settings, and as the need for cost-effective, proven, and noninvasive subsurface imaging continues to grow. In this article, we attempt to encapsulate the important factors that have fueled the growth of near-surface geophysics over the past few decades, and to project those which will influence the continued growth of this discipline in future.

Just as the Earth sciences underwent a renaissance of sorts in the 1960s and 1970s with the acceptance of plate tectonics, nearsurface geophysics experienced a smaller scale, but nonetheless exciting period of discovery and growth that began in the 1980s. The early years were characterized by widespread developments that included new instrumentation (e.g., GPR), new or adapted techniques (e.g., shallow seismic reflection profiling) and new interest and support for shallow geophysical investigations. There was growing interest in cooperation between engineers, geophysicists, hydrologists, and government agencies. Some in the academic community became actively involved in the field. Several factors could be cited as setting the stage for this period of growth in the United States with similar developments occurring elsewhere in the world:

- Spinoffs from the flux of basic research for the space program and other government efforts (e.g., basic research in GPR)

- Heightened awareness of environmental matters, due in part to highly publicized events such as the 1978 Love Canal disaster

- Greater government regulation (as exemplified by the formation of the Environmental Protection Agency in 1970, a few years before this period of growth) and requirements for documentation of site assessments such as environmental impact statements (part of the National Environmental Policy Act of 1969)

- Numerous closures and reutilization of Department of Defense facilities and associated need to characterize the impact of decades of military use on the near surface

- The rapid growth in the capacity of computers and digital electronics made new instruments possible and affordable, and enabled geophysicists to process and analyze data in a much more efficient manner

\section{Technological advances}

Many near-surface methods developed in the 1980s and 1990s were based on adaptation or scaling of techniques originally developed for mineral prospecting, petroleum exploration, or more academic studies. Over time, the methods have become much more sophisticated and refined. We will highlight a few areas of technological advancement that have been particularly important.

Higher efficiency. Several improvements have been made to seismic site assessment methods, related to the SASW (spectral analysis of surface waves) methods developed by Ken Stokoe and his colleagues (Nazarian et al., 1983). MASW or multichannel analysis of surface waves (Xia et al., 1999) was originally conceived as a way of utilizing surface waves contained in seismic reflection data in order to draw more benefit from those profiles, but has increasingly become a stand-alone technique. Passivesource surface-wave methods have also emerged and can utilize cultural noise to provide a low-cost and effective approach (Park et al., 2005). The effort and cost associated with invasive coupling of seismic receivers (planting) has lead to the development and advancements in towed spreads or landstreamers for near-surface applications (Van der Veen and Green, 1998). More recently, Ryden et al. (2006) introduced methods utilizing noncontact acoustic receivers. The importance of these surface-wave methodologies in site analysis for engineering design is immense, and should continue to expand as new variants and applications are developed.

In GPR studies, the last ten years have seen development of multichannel systems that are now available from all major hardware vendors. This new technology now enables efficient 3D swath mapping with common-offset GPR, simultaneous acquisition with multiple frequency antennas, and acquisition of common-midpoint-type data. As with the advent of efficient multichannel acquisition in seismic acquisition decades ago, the 


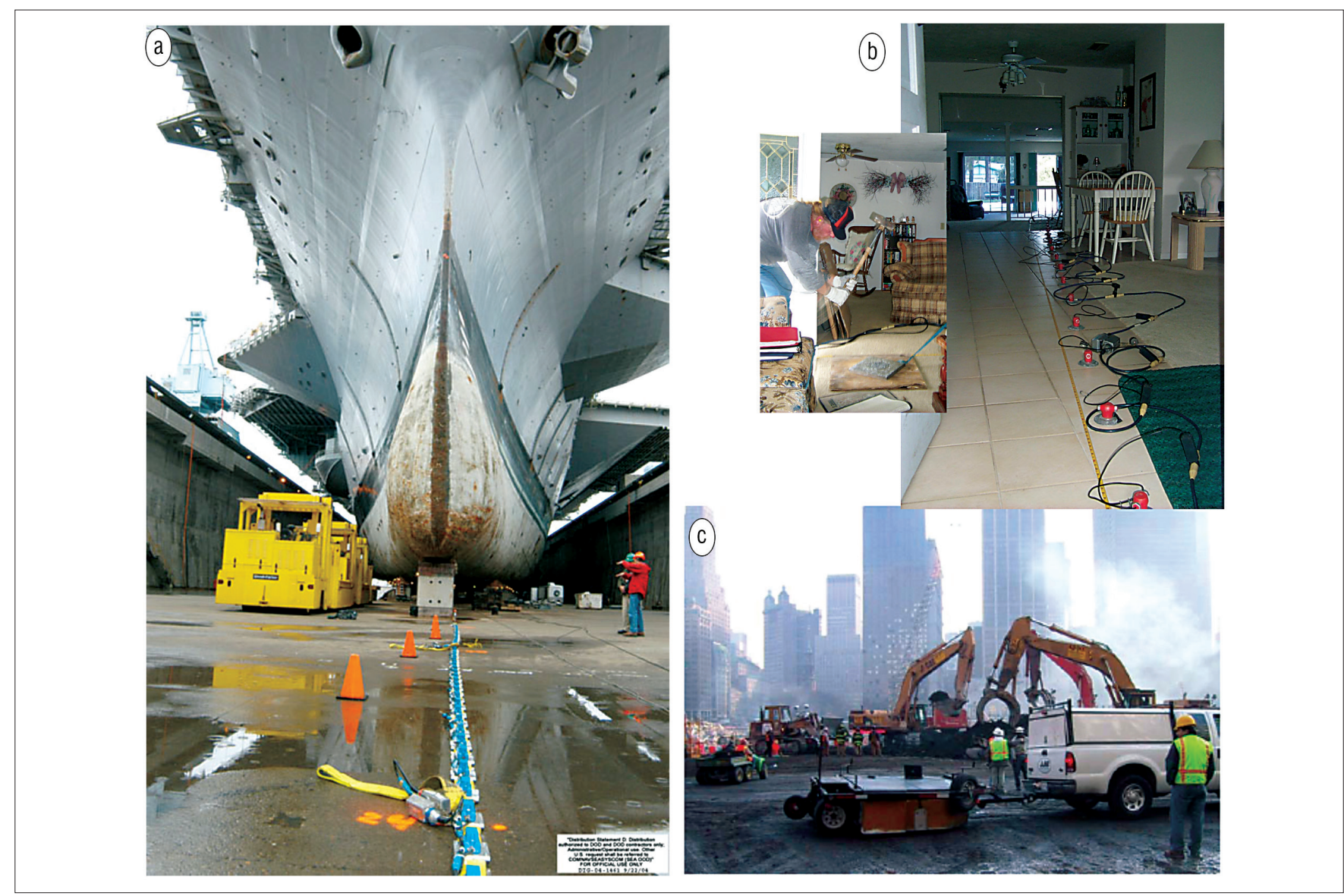

Figure 1. Geophysical data acquired in difficult settings: (a) seismic reflection data acquired in a shipyard (John Clark, personal communication), (b) MASW seismic data acquired through a house (Miller et al., 2000), and (c) radar acquisition in New York (Birken et al., 2002).

GPR community is beginning to realize the wealth of information the new hardware can provide and methodologies are still being developed.

Improved resolution and more dimensions. As with exploration seismic reflection in the 1980s and 1990s, the need to accurately image 3D geometries and improve resolution is driving an ongoing transition in near-surface geophysics. For example, multi-electrode resistivity tools (electrical resistance tomography, or ERT) have enabled much greater detail in resistivity imaging than the $1 \mathrm{D}$ results that were available 30 years ago. At that time, multichannel acquisition systems didn't exist, so the only way to acquire the data was by tediously moving electrodes in a complicated sequence. Without an efficient data acquisition method, it was fruitless to devise a multichannel analysis scheme. Now, data for two-dimensional images can be acquired with a simple field setup and evaluated alongside seismic refraction tomograms and other data to provide greater insight into site properties (Watson et al., 2005).

More recently, instrument and software providers have capitalized on this area of near-surface research and begun to promote $3 \mathrm{D}$ acquisition and analysis systems for resistivity. For sites where 2D structures do not adequately represent reality, 3D methodology offers higher resolution (as compared with 2D approaches), and better representation of actual structure. If the structure is not two-dimensional, a 2D inversion, however detailed, may be unsuitable. For example, assessing a contamination plume or mapping the saprolite-bedrock transition zone may require 3D imaging.

These developments have occurred within a broad range of methods. Seismic refraction analysis, once limited to conventional quasi-one-dimensional constant-velocity solutions, can now be addressed with tomographic codes and in three dimensions (Zelt et al., 2006). Velocity models which allow fully three-dimensional solutions are much more representative of many shallow conditions than layered models. Initially, some evidence for using such an approach was based on tomographic codes embedded in petroleum seismic reflection software. The solutions from these codes were better, but an improved tomographic solution was appropriate to estimate the actual velocity structure. Such codes are now available and routinely used for many shallow problems (Sheehan et al., 2005). Plenty of evidence indicates that users must be aware of the risks that accompany this approach, specifically those associated with nonuniqueness (Ivanov et al., 2005), and these concerns are the subject of recent workshops (e.g., SAGEEP's 2012 workshop "Seismic refraction methods: Unleashing the potential and understanding the limitations") and ongoing discussion and research (e.g., Zelt, 2012; Palmer, 2012). Improvements in seismic refraction analysis soft- 
ware can now provide a better solution than conventional layercake methods for addressing some shallow problems, e.g., karst sites, where the premises upon which earlier analysis tools were developed were inappropriate for the structure of these features.

Improved computational capabilities. Many types of analysis are possible today that were inconceivable 20 years ago, due to improved computational speed and software tools. For electrical resistivity practitioners, for example, layered Earth interpretations were the norm in 1987, and inverse modeling was a developing research topic. Now two-dimensional inversions have become routine, and 3D analyses are quite common. Following developments in seismic exploration, in GPR analysis, full-waveform inversion methods are being developed to take full advantage of the information contained in the recorded data (Meles et al., 2010; Belina, 2009).

Without a doubt, modeling and inversion throughput and reductions in cell size have greatly benefited from the computing revolution. Numerical operations are possible today that were once inconceivable or purely conceptual. The greatest impact on the near-surface community has been the reduced cost of computing capabilities rather than the capabilities themselves. Economically constrained near-surface projects now benefit from advanced computational capabilities that used to be exclusive to the energy sector. Massive increases in the redundancy of shallow data sets have in some cases boosted resolution and increased signal-to-noise ratios. For some methods, this has dramatically extended the imagining capabilities (resolution, depth, areal extent, etc.).

Advances in computational capabilities have made the near surface a more important consideration in modeling seismic response from deeper, exploration structures and lithologies. Models have been developed for petroleum exploration targets that address the problems of highly complex and challenging marine settings, fully testing the capabilities of both processing algorithms and acquisition designs (SEG SEAM I). The success of SEAM I has been the catalyst for the next and even more challenging model setting-land (SEG SEAM II). What makes this second modeling effort so difficult and computationally taxing is primarily related to the addition of the near-surface. The relative uniformity of the homogeneous water layer in marine settings almost eliminates the complexities (collectively classified as statics problems) of most terrestrial settings. Advancing the technologies and tools for land petroleum exploration as envisioned under the SEAM II project requires understanding, and compensating for, the vast heterogeneities of the near surface.

Joint inversion of multiple data types. With essentially all geophysical inversion problems having a significant level of nonuniqueness, and multiple data types having overlapping sensitivities to subsurface properties, it is well-recognized that combining multiple data types can help reduce uncertainty in the subsurface models. Indeed, this is one area in which near-surface geophysics has an advantage over deeper investigations. It is not uncommon for dc resistivity, GPR, seismic, microgravity, EM, and magnetics to provide complementary data at a given site. Joint inversion of multiple data types can be done either deterministically (e.g., Linde and Doetsch, 2010) or within a geostatistical framework (e.g., Paasche et al., 2006). A significant problem in joint inver-

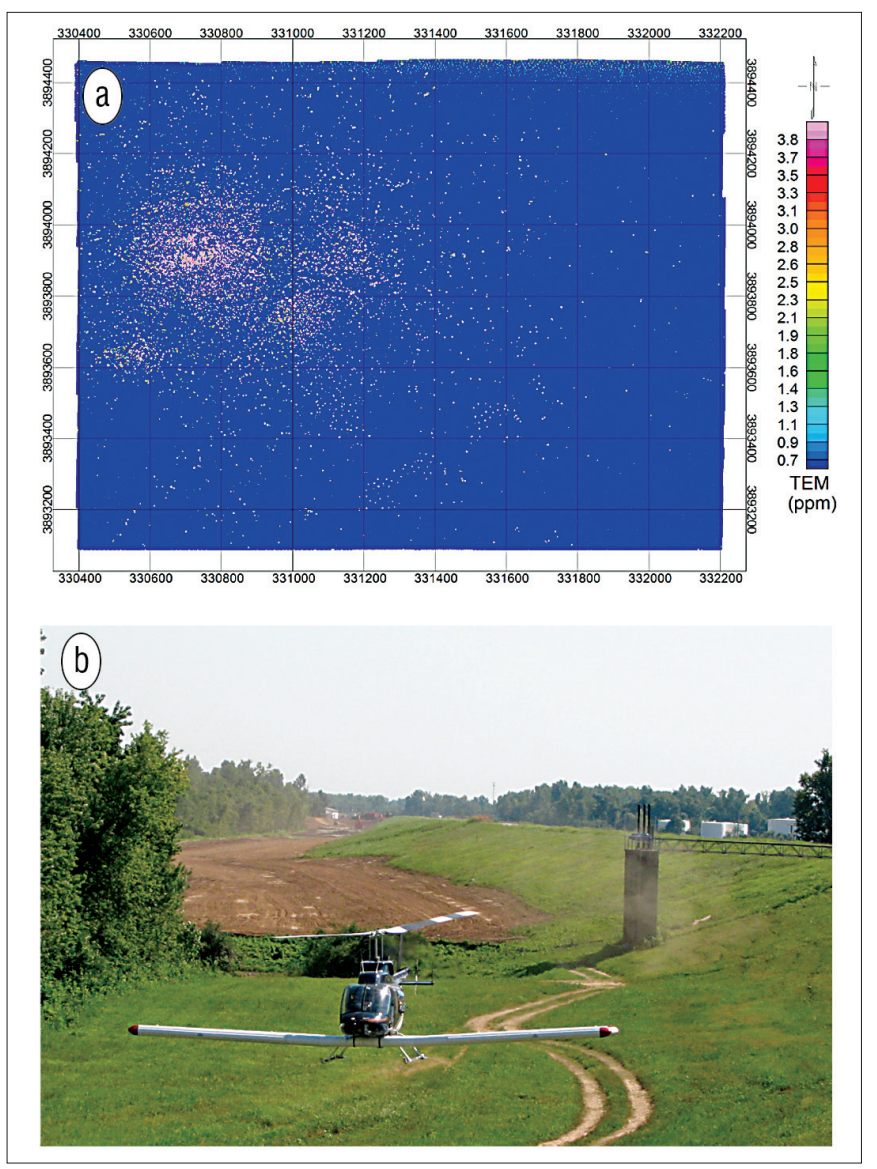

Figure 2. (a) Airborne electromagnetic map of a 250-hectare (617acre) bombing target; (b) Battelle TEM-8 system, acquiring data along a levee system.

sion is the different support volumes to which different data types are sensitive and we expect that this will continue to be an important area of research.

Dealing with cultural interference. Not only have new methodologies, sensor systems, and analysis methods been developed, but we find these (or other) methods being applied at sites where cultural noise or manmade interference that would have precluded operations in earlier years. As examples, Figure 1 shows radar data being acquired at a construction site (Birken et al., 2002), MASW data being acquired through the middle of a house (Miller et al., 2000), and seismic reflection data being acquired along a ship in dry dock. Work in these types of settings is becoming more commonplace, as it must in order for geophysical methods to be useful for many engineering and characterization problems.

Improvements in instrumentation over the last 30 years have included increases in dynamic range, number of recording channels, processing speed, and onboard storage. These have allowed data with low signal levels to be recorded with increased redundancy and fidelity, and low enough $\mathrm{A} / \mathrm{D}$ noise thresholds so that useful signal may now be extracted in the presence of what historically would have been prohibitive levels of cultural noise. Noise thresholds for many sensor systems have dropped, allowing signal previously unrecovered in noisy settings to be exploited. Challenges still lie ahead in spite of these monumental 


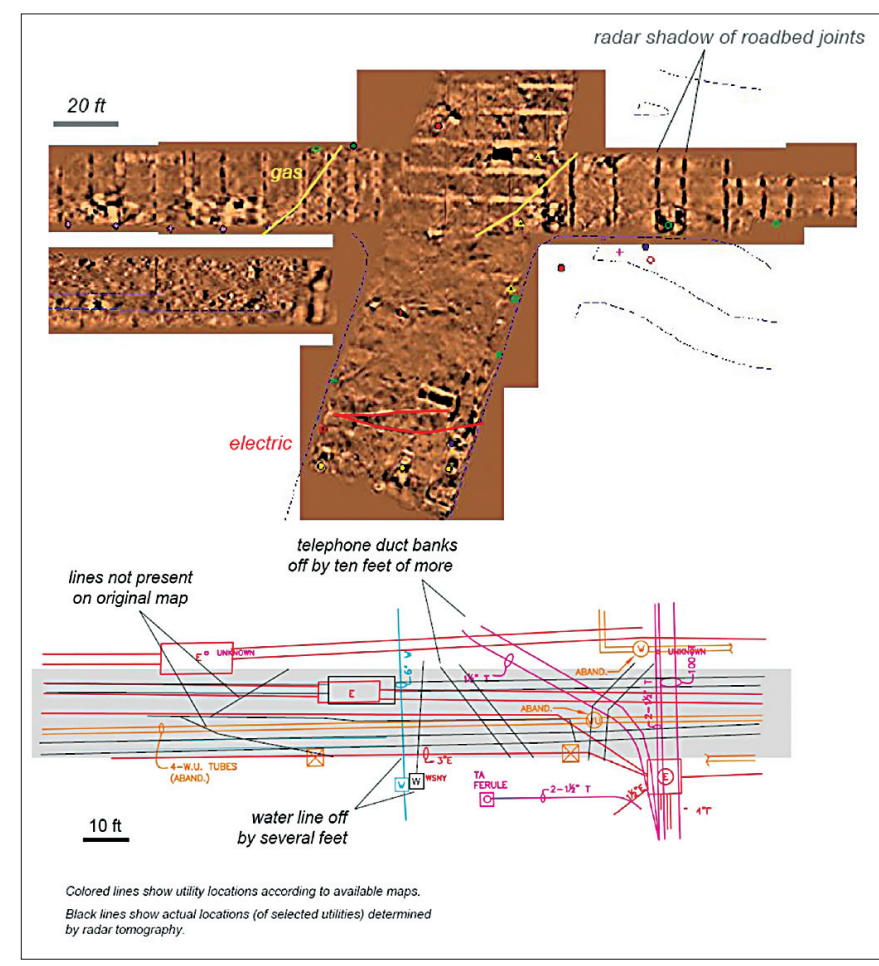

Figure 3. Radar image at 42-in depth, and resulting map view for a portion of the study area, showing corrections for infrastructure locations, (from Birken et al., 2002)..

improvements in acquisition hardware and software and processing algorithms. Interference from certain types of cultural noise still renders some methods ineffective.

Global growth has caused many sites that were previously void of anthropogenic noise to now become overwhelmed by it. The potential impact of various geohazards on people, property, and the environment in previously undisturbed or isolated nearsurface settings has been elevated to the point that geophysics is being attempted in extremely noisy and congested settings. Although data from such noisy settings can be ambiguous or difficult to interpret, in many cases geophysics represents the only option for noninvasively appraising the subsurface in high-risk, noisy and congested settings.

New tools to address new problems. With growing concern over ordnance contamination issues and a congressional mandate to close many military bases and return the land to public use came a need for methods to detect and characterize unexploded ordnance (UXO), now more commonly referred to as "munitions and explosives of concern" (MEC). It was recognized at an early stage that magnetic and electromagnetic techniques were optimal for characterizing former bombing or artillery ranges. Considerable applied research funding has been devoted to development of geophysical technologies that could expedite assessments of areas containing MEC (Butler, 2001). These studies have focused on methods for three primary issues: (1) improving the sensitivity of geophysical sensors to common types of ordnance; (2) increasing the rate at which areas can be surveyed; and (3) improving sensor and data analysis methods to enable discrimination between potentially live ordnance items

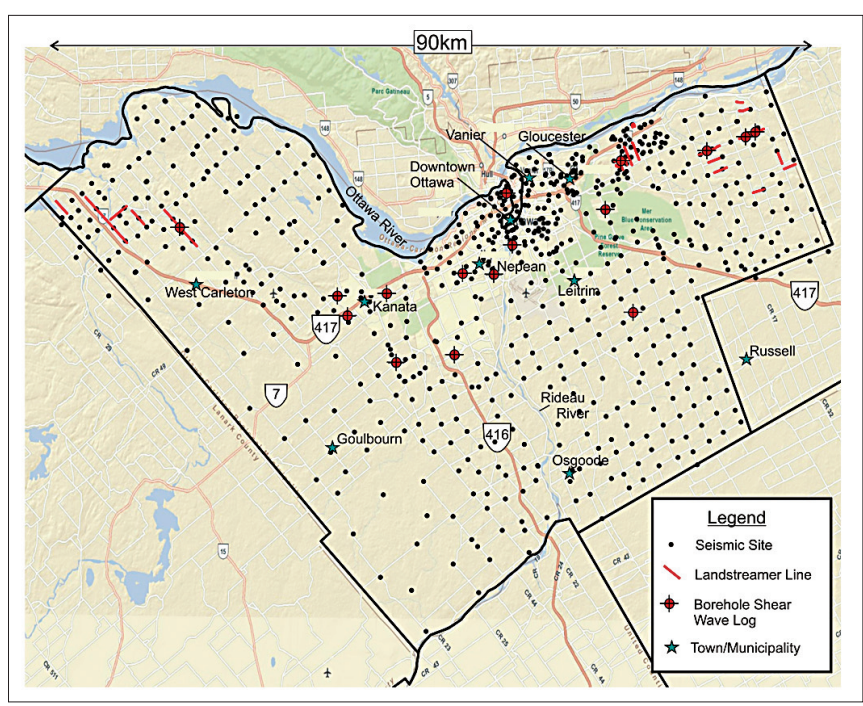

Figure 4. A suite of geophysical methodologies have been used to develop a high-quality earthquake microzonation map of Ottawa, Canada. (from Hunter et al., 2011).

and nonordnance or inert ordnance. The third topic can result in reductions in the extent of follow-up digging of anomalies, which can lead to large reductions in the overall cost of remediation. These programs have resulted in development of many new ground-based and airborne sensor systems and more sophisticated data analysis methods that will feed into a broader range of applications.

Airborne magnetic and electromagnetic technologies that have been designed for mapping and detection of unexploded ordnance over tracts of thousands of acres and larger (Doll et al., 2008) are equally suitable for many engineering problems. They have recently been applied to levee assessment, for example. These methods will eventually be deployed on unmanned autonomous or remote control vehicles. Other technologies at a similar stage of development will be available for future generations with new problem sets.

\section{Regulatory acceptance and client awareness}

Although the utility and value of geophysical methods may be obvious to geophysicists and to geoscientists in general, they are not always as apparent to potential clients. The users of geophysical assessments are often engineers, and they have stringent requirements for acceptance of the data and associated interpretations. Geophysical data can have error bars that carry too much uncertainty for engineers to accept. It has taken time to breach the gap between data accuracy and data value with these clients.

Geophysicists have had to develop more structured data analysis and assessment methods, and engineers have had to come to grips with some of the more qualitative benefits of geophysical surveys. Precise and accurate measurements in a dense array of boreholes may not provide adequate characterization of the intervening volume, and can be costly when compared to geophysically driven selection of a sparser array of boreholes. This principle has been recognized in the petroleum and mining industries for decades (and made for more economic extrac- 
tion of Earth resources), and is increasingly gaining acceptance among those who must quantify the uppermost portion of the Earth's crust.

Part of the growth of near-surface geophysics over the past few decades can be tied directly to many past conversations between geophysicists and project managers working together to breach this gap. Much effort has been devoted to developing ASTM standards and procedures for many different methods. The net result is that near-surface geophysics has gained programmatic acceptance in many areas. The work is not completed, but the progress is substantial.

Hesitation by engineers and program managers to employ geophysical methods is understandable in situations where these benefactors have previously encountered underqualified or unethical purveyors of the trade. Greg Hodges addressed this matter in his 2005 SAGEEP paper "Voodoo methods: Dealing with the dark side of geophysics." He developed a "Scamolyzer" for assessing the credibility of unfamiliar solicitations. Charlatans cause unnecessary doubts to be raised about viable methodologies when they misinform the user community about suspect methods or oversell credible, established methods. When discussions should be centered on whether a particular geophysical method can support a particular need, lingering doubts cause appropriate methodologies to instead be dismissed out of hand. That approach is detrimental to both the user community and the geophysical suppliers.

Obviously, these observations cover a small portion of the developments that have occurred over the past 30 years, and show a bit of bias toward the authors' realm of experiences. It's beneficial for each of us to look back and reflect on how the growth in technology has impacted our realm of interest over the recent past.

\section{What lies ahead?}

As we indicated at the beginning of this article, the continued growth of near-surface geophysics is widely anticipated. Several factors are likely to drive this growth, and we attempt to summarize some of those in the ensuing paragraphs.

Population growth. It is estimated that the Earth's population recently surpassed 7 billion according to the U.S. Census Bureau and United Nations. This number is expected to rise to 9.4 billion by 2050 , when today's college graduates will be approaching retirement. The increase in population is increasing the demand for natural resources and energy, and increasing stress on the environment. The greatest rate of change has been and is projected to continue to be in Africa. Many of the growth areas in nearsurface geophysics are tied to this growth in one way or another.

Aging infrastructure and sustainable development. As the world continues to become more crowded, the role of geophysics will continue to grow in many applications supporting environmental assessments and site remediation but at lower cost and in reduced time. Even in affluent nations, aging infrastructure fails at rates faster than the pace of repair or replacement. The 2007 Minneapolis bridge collapse is one of many examples. Unfortunately, even postconstruction diagrams (not to mention design drawings) do not accurately represent the locations of all 


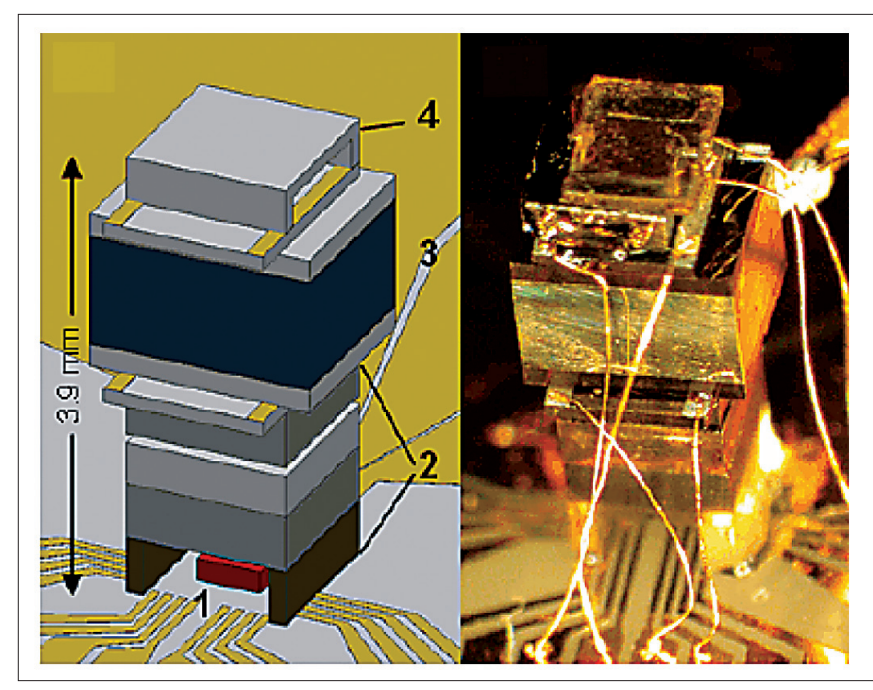

Figure 5. Original "chip scale" atomic magnetometer (CSAM) developed by the National Institute of Standards and Technology (NIST), forming the basis of further commercial development by Geometrics Inc. (from Schwindt et al., 2004).

cables, pipelines, or other elements of infrastructure that must be known in advance of excavation. The advantages of geophysical characterization and mapping of utility lines, tunnels, and other key subterranean infrastructure necessary to support modern urban life (e.g., Figure 3), will become more pronounced in the years ahead. Seismic microzonation is also receiving more attention, and will become more critical as urban areas expand and structures become larger (e.g., Figure 4).

Sustainable development has grown from being a distant concept to a buzzword in science, engineering, and business; a word that is actively and purposely incorporated in many projects. Development of sustainable cities will require a deeper understanding of the near-surface environment affecting infrastructure and buildings, and tighter monitoring and controlled disposal of wastes. Geophysical methods will also find application in monitoring to recognize as early as possible the risks associated with changes in the environment.

Structural and civil engineers are requiring better and more continuous site response and physical properties than possible with grid drilling (voxel level physical properties). Extrapolation between widely spaced wells will not be sufficient to model site response. Construction zoning regulations will vary based on smaller and smaller areas that without near-surface geophysics will be defined by gross interpolation of sparsely mapped lateral heterogeneities. Development costs can vary by orders of magnitude depending on how a property is zoned.

Risks to people and property escalate as modern civilizations knowingly or unknowingly encroach on geohazards that ancient civilizations have deliberately or inadvertently avoided. The majority of geohazards carry risks to ground stability, whether through subsidence, ground motion, slope stability, erosion, eruption, or some combination of these effects. Effective risk reduction to the degree necessary to sustain future growth will require a high level of 3D detail, including high-resolution (spatial and vertical) near-surface geophysical investigations.
Water. A particular need is for a clean water supply. By 2050, 25 percent of the people on Earth will live in countries in which water is permanently scarce. Contaminated drinking water is a major cause of disease and death in developing countries. An adequate water supply is a prerequisite for human existence, not only for drinking, but also for agriculture. Degradation of soils also poses a direct threat to food production in developing countries. The availability of arable land is decreasing. Population growth is complicating the situation. According to the International Red Cross, there are more refugees from a deteriorating environment than from war (Adams, 2005). Others warn that water quality will play a growing role in regional conflicts and wars. Hydrogeophysics has become an important topic of research, conferences, and workshops. Geophysical methods will be needed to map aquifers and pollutants to address these needs.

World economic development. Global economics and the emergence of China and India as major factors in the world economy are already impacting our daily lives. What will happen when these nations have achieved economic parity, and the environmental after effects of their rapid growth must be addressed? Recent and pending biennial conferences in China (ICEEG 2004, through 2012) are already preparing a domestic near-surface community in China to meet this need.

Expanding demands for security and peace. Near-surface geophysics is finding peaceful applications within areas of human conflict. Covert threats have been a part of war since prehistoric times, exploited by most ancient societies (Romans, Chinese, Egyptians, Persians, Greeks, etc). In the past two centuries, these have become more sophisticated in global conflicts (WWI, WWII, Korea, Vietnam, Middle East, Iraq, Afghanistan, etc). Discovering and eliminating subterranean passages (designed for sinister usage) and shallow buried explosives can reduce the toll on humanity and can effectively shorten conflicts. During ancient times, it was left to the human ear to detect clandestine intruders; now we have geophysics.

Applications of near-surface geophysics to land mines (including improvised explosive devices or IED) and underground facility detection will continue to be areas of active research as human conflict continues to morph. Some of the most promising advances will likely come from major applied research efforts by governments searching for clandestine threats. Cross-pollination between tools and techniques developed for engineering, groundwater, and environmental applications and advances specifically targeting security and defense problems will continue to act as catalysts for innovation in applied near-surface geophysics.

Computers and electronics. Further technological advances will certainly influence future applications of near-surface geophysics. Many papers presented at a special "Pioneers" session at SAGEEP 2007 focused on changes that occurred over the preceding 20 years. In his presentation, Gary Olhoeft provided some interesting insights into factors that will influence future technological advances. These included the innovations of nanotechnology, "smart systems," and developments associated with planetary exploration. Specifically, we are already seeing the capability of placing entire sensor systems on 2-3 low-cost chips, enabling acquisition of petabyte (1015 bytes) data sets.

"Smart systems" are now being developed that can "self-cali- 
brate, verify, and validate all steps from data acquisition through archival storage, processing, modeling, and interpretation" with sensitivity analysis and error analysis (Olhoeft, 2007). These advances are already influencing geophysical sensors. For example, CSAM or "chip-scale" cesium vapor magnetometers (Figure 5) are already in development (Prouty, 2006). We will need improved methods for handling large data sets to make effective use of these advances. Advances in parallel computing and further down the road will enable inversion and analysis that is beyond the reach of current systems.

\section{Conclusions}

Over the past 30 years, geophysical technologies have demonstrated increasing relevance to a broad range of scientific, societal and industrial problems, due to improved reconnaissance, efficiency, and resolution. Technology will continue to expand, and new applications will be found. We must continue to embrace new technological opportunities and to cooperate with domestic and international colleagues so that our discipline can have greatest benefit to future generations. TIEE

\section{References}

Adams, D., 2005, 50m environmental refugees by end of decade, UN warns; article in The Guardian, 11 October 2005, online at http:// www.guardian.co.uk/environment/2005/oct/12/naturaldisasters.climatechangel.

Belina, F. A., J. R. Ernst, and K. Holliger, 2009, Inversion of crosshole seismic data in heterogeneous environments; comparison of waveform and ray-based approaches: Journal of Applied Geophysics, 68, no. 1, 85-94, http://dx.doi.org/10.1016/j.jappgeo.2008.10.012.

Birken, R., D. Miller, M. Burns, P. Albats, R. Casadonte, R. Deming, T. Derubeis, T. Hansen, and M. Oristaglio, (2002), Efficient large-scale subsurface underground utility mapping with a multichannel groundpenetrating imaging radar system: Proceedings, 2002 Symposium on the Application of Geophysics to Environmental and Engineering Problems.

Butler, D. K., 2001, Potential field methods for location of unexploded ordnance (UXO): The Leading Edge, 20, no. 8, 890-895, http:// dx.doi.org/10.1190/1.1487302.

Doll, W. E., T. J. Gamey, L. P. Beard, J. R. Sheehan, and J. Norton, 2008, Advances in airborne geophysical systems for ordnance mapping and detection: The Leading Edge, 27, no. 11, 1463-1469, http://dx.doi. org/10.1190/1.3011018.

Hodges, G., 2005, Voodoo methods: Dealing with the dark side of geophysics: Proceedings, 2005 Symposium on the Application of Geophysics to Environmental and Engineering Problems, 315-327.

Hunter, J. A., D. Motazedian, H. L. Crow, G. R. Brooks, R. D. Miller, A. J-M. Pugin, S. E. Pullan, J. Xia, 2011, Near-surface shear wave velocity measurements for soft soil earthquake hazard assessment: Some Canadian mapping examples, in R. D. Miller, J. D. Bradford and Klaus Hollinger ed., Advances in Near-Surface Seismology and Ground-Penetrating Radar: SEG.

Ivanov, J., R. D. Miller, J. Xia, D. Steeples, and C. B. Park, 2005, The inverse problem of refraction travel times, Part I: types of geophysical nonuniqueness through minimization: Pure and Applied Geophysics, 162, no. 3, 447-459, http://dx.doi.org/10.1007/s00024-004-2615-1.

Linde, N. and J. A. Doetsch, 2010, Joint inversion of crosshole GPR and seismic traveltime data; in R. D. Miller, J. H. Bradford, and K. Holliger eds., Advances in near-surface seismology and ground-penetrating radar: SEG.

Meles, G. A., J. van der Kruk, S. A. Greenhalgh, J. R. Ernst, H. Maurer, and A. G. Green, 2010, A new vector waveform inversion algorithm for si- multaneous updating of conductivity and permittivity parameters from combination crosshole/borehole-to-surface GPR data: IEEE Transactions on Geoscience and Remote Sensing, 48, no. 9, 3391-3407, http://dx.doi. org/10.1109/TGRS.2010.2046670.

Miller, R. D., J. Xia, C. B. Park, and J. Ivanov, 2000, Shear wave velocity field from surface waves to detect anomalies in the subsurface: Proceedings of the International Conference on Applications of Geophysical Technologies.

Nazarian, S., K. H. Stokoe III, and W. R. Hudson, 1983, Use of spectral analysis of surface waves method for determination of moduli and thicknesses of pavement systems: Transportation Research Record, 930, 38-45.

Okada, H., 2003, The microtremor survey method: SEG Geophysical Monograph Series 12.

Olhoeft, G., 2007, Adventures in seeing the unseen-from borehole to the moon: Proceedings, 2007 Symposium on the Application of Geophysics to Environmental and Engineering Problems, 323-331.

Paasche, H., J. Tronicke, K. Holliger, A. G. Green, and H. Maurer, 2006, Integration of diverse physical-property models: Subsurface zonation and petrophysical parameter estimation based on fuzzy c-means cluster analyses: Geophysics, 71, no. 3, H33-H44, http://dx.doi. org/10.1190/1.2192927.

Palmer, D., 2012, Uncertainty in near-surface refraction inversion: Proceedings SAGEEP 2012.

Park, C. B., R. D. Miller, N. Ryden, J. Xia, and J. Ivanov, 2005, Combined use of active and passive surface waves: Journal of Environmental \& Engineering Geophysics, 10, no. 3, 323-334, http://dx.doi. org/10.2113/JEEG10.3.323.

Prouty, M. K., Smith, J. Kitching, and D. Serkland, 2007, A micro-fabricated total-field magnetometer: Proceedings, UXO Forum 2007.

Ryden, N., M. J. S. Lowe, P. Cawley, and C. B. Park, 2006, Noncontact surface wave measurements using a microphone: Proceedings, 2006 Symposium on the Application of Geophysics to Environmental and Engineering Problems, 1110-1115.

Schwindt, P. D. D., S. Knappe, V. Shah, L. Hollberg, J. Kitching, L. Liew, and J. Moreland, 2004, Chip-scale atomic magnetometer: Applied Physics Letters, 85, no. 26, 6409-6411.

Sheehan, J. R., W. E. Doll, D. B. Watson, and W. Mandell, 2005, Detecting cavities with seismic refraction tomography: Can it be done?: Proceedings, 2005 Symposium on the Application of Geophysics to Environmental and Engineering Problems, 989-1003.

Watson, D. B., W. E. Doll, T. J. Gamey, J. R. Sheehan, and P. M. Jardine, 2005, Plume and lithologic profiling with surface resistivity and seismic tomography: Ground Water, 43, no. 2, 169-177, http://dx.doi. org/10.1111/j.1745-6584.2005.0017.x.

Van der Veen, M., and A. G. Green, 1998, Land streamer for shallow data acquisition: valuation of gimbal-mounted geophones: Geophysics, 63, no. 4, 1408-1413, http://dx.doi.org/10.1190/1.1444442.

Xia, J., R. D. Miller, and C. B. Park, 1999, Estimation of near-surface shear-wave velocity by inversion of Rayleigh wave: Geophysics, 64, no. 3, 691-700, http://dx.doi.org/10.1190/1.1444578.

Zelt, C. A., A. Azara, and A. Levander, 2006, 3D seismic refraction traveltime tomography at a shallow groundwater contamination site: Geophysics, 71, no. 5, H67-H78, http://dx.doi.org/10.1190/1.2258094.

Zelt, C., J. Chen, and P. Jaiswal, 2012, Combining frequency-dependent traveltime tomography and frequency-domain waveform tomography for near-surface seismic refraction data: Proceedings, SAGEEP 2012.

Corresponding author: dollw@battelle.org 


\section{The SEQ near-surface geophysics initiative}

For over a decade, SEG has maintained that near-surface geophysical applications are an important component of its mission and vision. Despite this recognition, opportunities and decisions have been addressed ad hoc and there has not been a sustained effort to foster services and growth for SEG's near-surface members. As a result, little progress has been made in broadening SEG's base while other organizations such as the American Geophysical Union's (AGU) Near-Surface Focus Group have flourished. To ensure that SEG takes a leadership role in supporting and advancing this burgeoning area of applied geophysics, the 2010 SEG Executive Committee approved a strategic plan with the intent to grow the NS membership. Key components of the plan are:

- Leadership: A task force to work with SEG's Near-Surface Geophysics Section (NSGS) to refine and lead the implementation of the strategic plan.

- Communication: Work to ensure that SEG is recognized by the near-surface community as the leading organization for applied theory and technology development.

- Structure: Create SEG structure and administration that enables and insures a stronger voice for the SEG near-surface community.

- Meetings and publications: Establish high-visibility, ongoing programs at the Annual Meeting. Partner with local or regional organizations internationally to hold joint meetings, workshops, and forums and to develop publications from those activities.

- Continuing Education: Establish a suite of continuing education programs that includes lecturers and formal topical courses in near-surface geophysics.

- Water: Establish a high profile for hydrogeophysical applications.

- Growing Membership: Outreach to groups that do not currently have a significant presence in SEG including engineering, infrastructure, forensics, and archaeology.

The Near-Surface Task Force (NSTF), created as a result of the strategic plan, held its first meeting at the 2010 Annual Meetting in Denver. NSTF has made substantial progress and the results are summarized below.

The 2011 Executive Committee unanimously approved funding for the Near-Surface Honorary Lecturer (NS HL). This is the first topical HL to be funded by SEG (all previous HLs have been regional) and, beginning in the Fall of 2012, will make approximately 20 stops annually.

The 2011 Executive Committee also approved a standing session at the Annual Meeting devoted to hydrogeophysics. Given the importance of water resources to society as a whole, the use of geophysics to characterize ground and surface water is critical. The importance of hydrogeophysics will only increase as stress on sources of fresh water continues to increase. Hydrogeophysics is one of the most actively growing areas of geophysics both in numbers of practitioners and researchers and in technological development.

A substantial issue in serving the near-surface community is its current fragmentation. This fragmentation arises for at least two reasons: (1) the diversity of applications leads to compartmentalization by subdiscipline (e.g., engineering, infrastructure, hydrology, archaeology, forensics), and (2) economics. Most near-surface geophysicists work with small budgets and long-distance travel is limited. SEG's global reach and digital infrastructure puts it in a good position to overcome some of these barriers.

In 1992, members of what was then called the SEG Engineering and Groundwater Geophysics (E\&GG) Committee split off to form an independent organization named the Environmental and Engineering Geophysical Society (EEGS). This organization has become a functioning independent society that operates in North America. At present, the objectives of the SEG Near-Surface Section and EEGS are essentially the same- to advance and promote the rigorous science, technology, and professional practice of geophysics as applied to near-surface problems. There is substantial overlap in membership, with nearly $50 \%$ of EEGS members maintaining SEG membership. Over the past few years, cooperation between SEG and EEGS has increased. SEG members can now access the EEGS journal, (Journal of Environmental and Engineering Geophysics), on the SEG Digital Cumulative Index as well as proceedings papers from EEGS's annual meeting. The Symposium for the Application of Geophysics to Engineering and Environmental Problems (SAGEEP). Over the past year, a joint task force that includes members of both SEG and EEGS has been evaluating how the two organizations might work even more closely together. Combining the strengths of the organizations can only benefit the community as a whole.

Finally, the SEG Near-Surface Task Force is developing a plan for continuing education. The plan follows a tiered structure that includes offerings at low or no cost, as well as full short courses that will meet professional licensing requirements. Within this structure, we hope to establish ties with other groups of applied geophysicists that have not traditionally had an affiliation with SEG.

An important component of SEG's near-surface geophysics efforts is expanding SEG's outreach and services to near-surface members outside of North America. For example, SEG cosponsored the International Workshop on Advanced GPR in Aachen, Germany, 2011, the 2010 and 2012 International Conferences on Environmental and Engineering Geophysics in China, and GPR 2012 in Shanghai, China. There is a large community of near-surface geophysicists in the Asian/Pacific region. At present SEG is engaging the affiliated societies in the region with the intent of establishing a recurring international meeting focused on near-surface geophysics that serves the western Pacific and improves communication to other parts of the world.

Stay tuned. These are the first of what will be a number of exciting new developments and member services to come out of SEG's near-surface strategic planning and implementation process. 